\title{
Brain birth and personal identity
}

\author{
D Gareth Jones University of Otago, Dunedin, New Zealand
}

\section{Author's abstract}

The concept of brain birth has assumed a position of some significance in discussions on the status of the human embryo and on the point in embryonic development prior to which experimental procedures may be undertaken on human embryos. This paper reviews previous discussions of this concept, which have placed brain birth at various points between 12 days' and 20 weeks' gestation and which have emphasised the symmetry of brain birth and brain death.

Major developmental features of brain development are outlined, including the gradualness with which new features generally appear, and also the electroencephalogram (EEG) characteristics of premature infants. From this it is concluded that, if the concept of brain birth is a valid one, it should be placed at 24-28 weeks' gestation. More importantly, it is concluded that the differences between brain development and brain death throw doubt on the concept itself.

Ways of handling the beginning of human life continue to perplex philosophers, theologians, ethicists, embryologists, and reproductive biologists alike. Of these, I shall focus on the concept of brain birth. At what point during development can the fetus be said to acquire a brain? Is this a meaningful question scientifically, and if it is does it have any philosophical signficance? My aim is to consider the concept itself and its scientific rationale.

\section{Theological glimpses}

Roman Catholic writers in the 1960s and 1970s discussed what they termed the hominisation of nascent life. This concept appeared to help answer the question of when individualisation occurs during fetal development. According to writers such as Karl Rahner and P Overhage (1) in the early 1960 s and Wilfried $\operatorname{Ruff}(2,3)$ around 1970 , hominisation can be related to the development of the cerebral cortex, since the latter constitutes the biological substratum for personal life. This emphasis on the cerebral cortex

\section{Key words}

Brain birth; brain-life theory; brain development; brain death; personal identity. may, itself, have owed a great deal to the anthropological concepts of Roman Catholic thinkers such as Teilhard de Chardin (4), who had previously argued that the human species had transcended itself by a major leap in the development of the cerebral cortex and that without such a development no specifically human personal attributes are possible.

This theme of hominisation was picked up by Bernard Häring (5) in the early 1970 s. According to Häring the decisive question is: ' $\mathrm{Can}$ a living being be a person at all without the development of the biological conditions and/or presuppositions of person life?' Häring considered that it is the cerebral corteß that is the central organ of all personal manifestation and activities. He also noted that the basic structure of a typically human cerebral cortex develops between days 15 and 40 gestation, and that anencephalics with their lack of a cerebrum are incapable of any personal activity. These observations enabled him to distinguish between biological and personal centres of life, recognising that there may be circumstances where the former exists without the latter. One such circumstance could be prior to the formation of the typically human cerebral cortex in early development.

The force of Häring's stance stenis from his perception that there is no qualitative leap in cortical development after days $\mathbf{2 5}$ or $\mathbf{4 0}$ gestation. According to him, further development is of a quantitative variety, consisting of elaboration of the basic cortical structure that has already been laid down. For Häring, this period between days 25 to 40 gestation marks a self-transcendence in basic brain structure, leading him to argue that prior to day 25 the embryo cannot with certainty be considered a human person. In spite of this, he errs on the conservative side ethically, since he does not consider that the evidence is strong enough to deprive pre-25-day embryos of the basic human right to life.

An alternative Roman Catholic perspective is that of Charles Curran (6) and Richard McCormick (7), both of whom argue against the significance of cortical development for personal identity. They consider that the basis for personal relations is not qualitatively 'that much more present because there is now a cortex in the brain' (6). Consequently, the emergence of a cortex is not regarded by them as a threshold. between non- 
personal and personal life.

An alternative neural attribute stressed by some writers is the establishment of a functioning nerve net at around 40 days' gestation. This has been held to constitute 'a necessary criterion for the beginning of personal life, paralleling the common acceptance of brain-death - as the mark of the end of physical life' (8). The reason for moving in this direction is to be found in the importance this view attaches to the phenomenon of consciousness for human existence. More specifically, the argument is that humans are to be defined in terms of a nature able to exercise rational, moral and personal capacities. If this is so, the beginnings of personal life may be found in the first moments of the conscious experience, since these constitute the basis of later rational thought. The argument is that, since consciousness provides the foundation for other attributes, such as rationality, the first conscious states are of moral significance. As these are dependent upon the development of certain neural structures, the human subject cannot take form in an embryonic body that has not yet reached 'the appropriate stage of differentiation and development' (8).

In criticising this subject-of-consciousness position, the authors of the report Personal Origins (8) contend that it lays claim to more knowledge about the correlation of consciousness and the organisation of the nervous system than is possible. Nevertheless, they accept that the neurological evidence that differentiated brain-activity does not occur until about 40 days after fertilisation helps to pin-point an important threshold in fetal development, one which many regard as morally decisive.

\section{Medical contributions}

In 1982 John M Goldenring (9), a Los Angeles paediatrician, put forward what he later termed the 'brain-life theory'. Utilising developments connected with the definition of brain death, he argued that one principle has come to the fore, namely, that the presence of a functioning brain signifies that a patient is alive.

Applying this principle to the fetus, and using EEG evidence, he considers that brain function is reliably present at about eight weeks' gestation. He also maintains there is a logical, medical equivalence between such an eight-week-old fetus whose respiratory function is maintained extracorporeally by a placenta, and an 80-year-old with a positive EEG whose oxygenation is facilitated by a mechanical ventilator. Since no physician would doubt that the 80 year-old is a living human being, even if comatose, the fetus at eight weeks must, he argues, be a living human being. Prior to eight weeks ('prior to full brain differentiation'), existence is limited to cells, organs, and organ systems which have the potential for integration into a full human organism, a potential that will be realised only if the brain develops further.

In elaborating on this theory, Goldenring defended the eight-week mark as the starting point for human (personal) existence, indicating in his view the point at which there is integration of the brain as a whole. This view he based on evidence that the subcortical brain comes into being as an organised unit at five weeks, with cerebral hemispheres differentiating at seven weeks, and EEG activity being demonstrated at eight weeks (the latter figure probably refers to the first appearance of EEG potentials in the lower brainstem). Any tissues or organ systems present prior to brain integration are un-co-ordinated and lack the ability to develop personality. The attractiveness of this theory, Goldenring contends, rests in the symmetrical view it offers of the beginning and end of human existence and on its objective basis.

Thomasine Kushner (11), in assessing this stance, argues that a particular point in development allows us only to set perimeters around a general range of functions. From this she argues that the initiation of brain activity is the most reasonable time at which to fix the start of life, not because there is some empirical argument that establishes it as such, but because of the connection of brain activity with the possibility of consciousness and the connection of this with what we take to be valuable about the notion of 'life'. For Kushner, the functioning brain makes possible the consciousness on which bios (having a life) depends. And so, although the embryo from fertilisationonwards has zoe (being alive biologically), this is not the same as being the subject of a life in the sense of bios.

From this she concludes that 'until it has developed a brain capable of consciousness the fetus's biography is not yet started. There is no life (bios) of which the fetus is the subject, although there are lives of which the fetus is a part' (11). Kushner's reasoning is that, apart from a functioning brain, the fetus cannot have any of the psychological attributes necessary to make it a human being who is the subject of a life. Kushner concedes that the person-forming process is a lengthy one, and that this is not accomplished by eight weeks' gestation. Nevertheless, she maintains that 'once a human fetus has developed a brain capable of consciousness its biography... has begun' (11).

In this argument 'capable of consciousness' appears to imply a potential for the development of consciousness as much as a present capacity for consciousness. If this is the case, it is not clear why eight weeks has been chosen as the critical developmental stage. This is crucial, since Kushner argues that before the development of a brain capable of consciousness the fetus has no intrinsic entitlement to protection of its life. Eight weeks, therefore, is being used as a critical marker. The question that remains is what neurological reasons there might be for concluding that an incapacity for consciousness becomes a capacity for consciousness once this point is passed.

Similar arguments are put forward by $M$ C Shea (12), who recognises that a new human life comes into 
being when the newly developing body organs and systems begin to function as a whole under the direction of a functioning brain. The commencement of this holistic level of life is placed at eight weeks' gestation, when all the characteristics of a species become fully potential. From eight weeks onwards, the organising principle stemming from brain activity is recognised by Shea as a distinct addition to the level of development and as crucial for the establishment of personhood.

A much later date for brain birth has been proposed by Gertler (13), whose concern is 'to propose brain birth as a realistic and legitimate basis for defining the point when legal protection of the fetus should begin'. On the basis that the necortex begins producing EEG waves between 22 and 24 weeks' gestation, he proposes 20 weeks' gestation as the legislative point at which a potentiality of life becomes a protectable right. Underlying this proposal is the view that human cognition is the beginning of cognitive capability and the point at which personhood protection should begin.

\section{Contributions stemming from the debate on the new reproductive technologies}

Although the contributions I am about to turn to do not assess the concept of brain birth as such, they do have a part to play in reasoning about the status of the human embryo.

For Clifford Grobstein (14) what matters is not the beginning of human life itself, but the manifestation of self. He contends that, until eight weeks' gestation, the human embryo lacks the two essential aspects of personhood: affective recognisability by other people and internal conscious awareness. Anything before this is a preperson, even a preembryo (15). He concludes, therefore, that it is impossible to violate the rights of persons in in vitro fertilisation. This conclusion is strengthened by an additional consideration, that since later embryonic development is impossible without implantation in a woman's uterus, preimplanted embryos have no special status.

Peter Singer and Deanne Wells (16), in their treatment of embryo research, contend that the newly created embryo is not entitled to a special moral status which makes it wrong to destroy it. Surplus embryos may, therefore, be created and used for research purposes, since such embryos are not the bearers of rights. In considering when, during the course of normal development the embryo becomes a being that has rights, they consider that consciousness, autonomy, and rationality are morally relevant characteristics, with consciousness being the most minimal of these. They argue that as soon as a being becomes capable of feeling pleasure or pain, or of having experiences and preferring some kinds of experience to others, that being has sufficient moral status to make it wrong to do certain things to it, such as inflicting pain upon it unnecessarily. Although unable to determine when the embryo becomes conscious, they suggest that the embryo be regarded as a thing, rather than a person, up to the point at which there is some brain function. This they put at six weeks at the earliest.

A somewhat different contribution is that of Donald MacKay (17), who divided early embryos into Xs and Ns. The Xs are those that are spontaneously aborted at too early a stage for any of the minimal structures necessary for recognisable personal life to have developed. The Ns, on the other hand, are those embryos that develop into normal infants and adults. In the case of the Xs, he doubts that there ever was a person with personal identity there. But if this is true, there must be some point during development when those fetuses which are going to 'make it' acquire the status of persons. MacKay recognises a decisive moment in the maturation of the nervous system before which there is nobody there, but after which there is someone who is 'he' or 'she' as a personal cognitive agent, however limited in capacities. In arguing like this he is not equating personhood with brain activity, since he regards the 'person' as belonging to a different category from neurons or neuronal networks.

The question, which has to be asked concerning both the Ns and Xs in MacKay's description, is the nature of an embryonic ' $I$ '. If the $N$ 's have an embryonic ' $I$ ' retrospectively, is this something that is bestowed only in retrospect? Or is there some meaningful way in which we can talk about an embry as a person with a sense of its own destiny and future?

One final pragmatic contribution is that of Robert Edwards (18). In discussing various ethical aspects of human embryo research, he proposed that the period between days 12 and 30 after fertilisation is a time to consider carefully, as it is during this period that the neural tissue appears and begins to develop. Since the forebrain begins to take shape at 30 days, he has stated his reluctance to culture embryos as this stage approaches.

\section{Where do we go from here?}

Certain common strands underlie the positions of writers who stress the significance of the appearance of what may loosely be referred to as a brain.

In the first place, emphasis is placed on a point during development when brain tissue begins to function. This is either because a functioning brain denotes a living person, or because a certain level of functioning denotes the integration of neural activity. From some decisive stage onwards the brain is thought to be acting in a holistic and co-ordinated fashion, as opposed one imagines to an unintegrated, individualistic fashion. The crucial question is what this functioning amounts to at six to eight weeks' gestation or even earlier.

The second theme for some of the writers is the crucial part played by the appearance of the cerebral cortex. The rationale for this is that it is the cortex which, in the postnatal human, is central to higher 
thought processes. While there is no denying that this is the case later on in life, the issue during early gestation is whether the first appearance of cortical progenitors signifies that the fetus has personhood or a personal centre of life. The features associated with personhood in postnatal life are only potentially present in the eight-week fetus; and so, this stance relies upon the potentiality argument. Surprisingly, though, this is not brought out by these writers.

A third, and closely related, theme used by a number of the writers is the appearance of consciousness at around six to eight weeks' gestation. Strictly speaking, what is important is the potential for consciousness, rather than consciousnesss itself. In some instances, what is being searched for is an awareness of sensations such as pain. This, however, can hardly be taken as characteristic of human life alone. It may be, therefore, that it is self-consciousness and rationality that should be stressed. These, however, are even further removed from what is present at around eight weeks' gestation, and so reliance must be placed once again on the potential of the early fetus for these traits.

The fourth theme is that of the symmetry between the acquisition of brain function at the beginning of life, and the loss of brain function at the end of life. This is the equation between brain birth and brain death. While this notion of symmetry has attractions, its validity is not as self-evident as some writers suggest. Brain death is the (gradual or rapid) cessation of function of a brain; brain birth is the very gradual acquisition of function of a developing neural system. Is this developing neural system a brain? At some point, it must become a brain, but at what point? In particular, can we legitimately call it a brain at around eight weeks' gestation?

\section{Development of the brain}

In order to put this debate in context we need to consider some of the major features of brain development. I have dealt with these in detail elsewhere (19), and I shall not repeat them here. Nevertheless, some of the stages referred to by other writers should be considered. By 32 days' gestation the five major regions of the future brain can be distinguished, with the cerebral hemispheres becoming distinct entities at six weeks. At around the same time, the cerebral cortex is taking shape. The eight-week stage, on which so much emphasis is placed, is characterised by the appearance of the neuronal populations of the cerebral cortex (the neurons being very immature at this age), while there are reflex movements (for example of the arms) in response to mechanical stimuli. Spinal reflex arcs may be recognised for the first time as distinct structures. There may also be slow spontaneous movements of the arms, legs and trunk. It is not until fourteen weeks at the earliest that very immature EEG activity can be obtained over limited areas of the cerebral hemispheres, and that there is responsiveness to pain (which is poorly localised at this stage). Both these features are problematic. The initial time of electrical activity appearance in the fetal brain is of an amorphous nature and hence difficult to determine with precision. With regard to pain, there is no way of knowing whether a behavioural response we would experience as pain is experienced in the same way by an early fetus with a rudimentary nervous system.

In view of these data, it is difficult to have any assurance that specific developmental ages can be associated with concepts such as differentiation or integration. Neither can one assert that there is 'conscious awareness' from the eight-week stage onwards.

The overwhelming impression of brain development is that of its gradualness - and also of the staggered manner in which the brain comes into being. The nervous system of the eight-week-old fetus is quite different from that of the seven- or eight-month-old fetus, let alone of the two-year-old child. Consequently, the nervous system of the eight-weekold fetus is not a miniature version of the young child's brain. It is very incomplete, and its functioning is at a totally different level from that of the late fetus or young child.

What follows from this is that, at present at least, it is impossible to recognise a distinct point of transition from a 'non-brain' to a 'brain', or from a nonfunctioning nervous system to a functioning one. This does not mean that there is no such transition point theoretically, only that it is not possible to talk meaningfully about one in practical terms. Whether or not this will ever be possible is a matter for debate.

What are possible are generalisations. Among these are the following: reflex activity appears long before 'conscious' activity; the spinal cord develops much earlier than the cerebral hemispheres, which are only capable of controlling movement at about the time of birth; each function first appears in an immature form; neurons appear fairly early, although they mature and make contacts with each other much later on (in the latter three months of gestation). The immaturity of the cerebral hemispheres even at eight to nine months' gestation is demonstrated by the relative immaturity of the EEG tracings at this late stage of fetal life.

In assessing brain development particular emphasis should be placed on certain features, such as myelination (development of myelin around nerve cell processes), synaptogenesis (development of synapses, that is, connections between neurons), and the development of networks between neurons. This is because these developments are essential constituents of an adequate physical basis for higher mental functions.

The development of myelin is essential for the normal development of the brain and spinal cord, and it may even be that an individual's acquisition of behavioural and psychological capacities is dependent on the extent of myelination of appropriate brain regions. However, the timing of myelination varies between different parts of the human central nervous 
system. For instance, it is first seen in the spinal cord during the fourth month of gestation, although even here it may not be completed until a few months after birth. In the brain the laying down of myelin commences at different times in different systems, from seven months of gestation until a few months postnatal.

The first synapses to be described in the human nervous sytem have been at eight weeks' gestation, although these are very few and far between and they are unlikely to be functional. A more characteristic description is of a few synapses at 23 weeks' gestation in the cerebral cortex. In general, however, the major production of synapses commences during the seventh month of gestation, and continues until about 18 months postnatal.

Also of importance for the functioning of the nervous system is the nature of the networks made by large numbers of neurons - within any one brain region and also between brain regions. The complexity and extent of these networks in the human brain are probably its most distinctive characteristic. In the motor cortex, which is the most developed area of the human cerebral cortex at birth, there are three major types of network. Only one of these (the system linking the cerebral cortex with deeper regions of the brain and the spinal cord) develops prenatally. The remaining two systems, which link up groups of neurons at different levels within the cerebral cortex and are fundamental to the development of higher mental functions, develop principally during the first two years after birth. In other words, the complexity of neuronal circuitry so essential for the manifestation of human attributes, only emerges as a feature of the human brain during the first two years after birth.

\section{Assessment of the brain birth concept}

In view of these very general developmental features, we now have to ask whether the brain birth concept is a meaningful one from a biological point of view. The idea that there is some point during development when the brain begins to function is modelled on the converse situation, namely, that at some point the brain ceases to function. When the brain is dead so, it is argued, is the person; the human life of that particular individual has come to an end. If this can be determined, can it also be determined when the brain commences its functioning? The analogy is a powerful one, and it is not unreasonable to argue that, at some particular stage during development, numerous discrete functions come together so that the rudimentary nervous system begins to function as a nervous system. When individual neural phenomena are integrated into a brain-like phenomenon, a brain is born at that developmental point.

The question confronting us is not whether this is theoretically convincing, but whether there is any way in which it might be recognised in practice. An illustration is provided by EEG criteria. As previously mentioned, the earliest very localised EEG activity appears at 14 weeks, with more generalised activity at 22-23 weeks' gestation. This activity, however, is discontinuous with long periods of electrocerebral silence, a characteristic of the immature nervous system (20). In other words, the EEGs from premature infants of varying developmental ages provide much the same picture as that provided by a study of the developing brain, and this is that the acquisition of an adult state of affairs is a long drawn out process. This renders the EEG unhelpful since the electrical inactivity of brain death is a normal feature of the developing brain, albeit for periods of time lasting from a matter of seconds to a few minutes. This lasts until about 32 weeks' gestation (20). If the EEG is to be taken as a guide to brain birth it is a highly conservative tool, placing the emergence of the semblance of an adult pattern at 32-36 weeks' gestation.

Two further points may also be relevant. The first is that when the EEG is used to determine the loss of brain function, it is dealing with an essentially all-ornone phenomenon, whereas the EEG when used to determine the beginning of function is concerned with a progressive process. During development it is required to indicate when an acceptable level of functioning is present, not when some functioning is present. Second, since EEG as an objective indicator of death is of questionable value $(21,22)$, it would appear seriously misleading to use it as an objective indicator of life in a much more tenuous situation.

The dominant feature of the developing brain is that different systems are laid down at different times, and these are not co-ordinated until relatively late in development. This is illustrated in Figure 1, from which it can be seen that some developmental sequences can only occur once the preceding sequence has been completed, for example, $b$ follows $a, c$ follows $b$ and $e$ follows $d$. This diagram also shows that some sequences, such as $g$ and $h$, occur late in development, while $h$ is not completed until after birth. If brain birth is placed at time ' 1 ', only sequences $a, d$ and $f$ are present, and even these have not been completed. No other sequence has commenced. At time ' 2 ', all the sequences are present, except for $g$ and $h$. By time ' 3 ', which is late in development, all developmental sequences are in place, even if further development is still to occur.

There is, therefore, no simple answer to when brain birth occurs, except to say that if it is placed early (such as at ' 1 ') numerous phases of development will not even have appeared. If the concept is to be used at all, it is preferable to place it at a time when most developmental sequences have started, for example, at ' 2 '. By reference to specific neurological data, this would place it at approximately 24-28 weeks' gestation.

This is, of course, an arbitrary conclusion, which is at odds with those who have put the emergence of the brain at anywhere between 12 days and eight weeks, although it is close to 20 weeks as advocated by Gertler (13) but for different reasons. It is also at odds with those who consider that the brain of the newborn is 


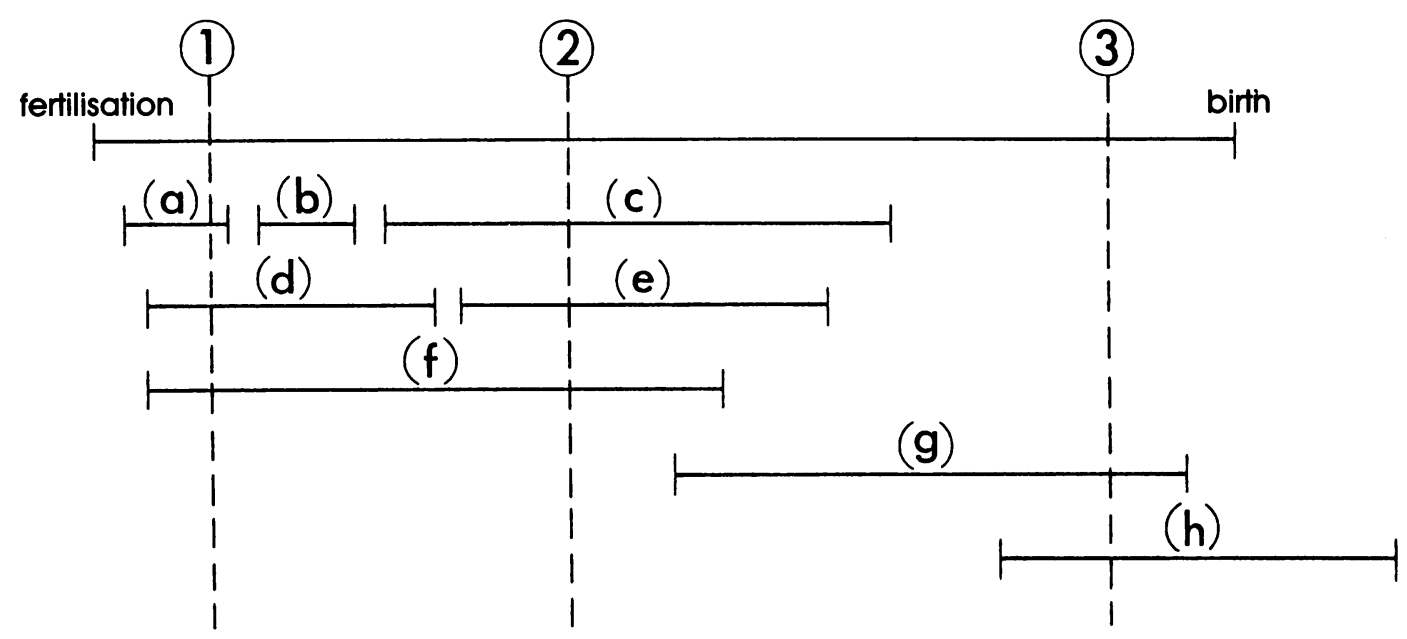

Figure 1: Illustration of the sequential manner in which the brain develops. a-h represent distinct sequences implicit in the development of the brain. For an explanation, see text page 177. From Jones reference (19).

incapable of a capacity for thought and rational deliberation, and who therefore bestow upon the newborn a non-personal status (23). Herein, lies our dilemma. If the concept of brain birth is used to demarcate the transition from non-personhood to personhood, it will have major repercussions for ethical decision-making. In this discussion I have attempted to ignore this consideration, although this does not mean that my placement of brain birth at 24 to 28 weeks' gestation is correct, or even helpful.

My conclusion, however, is that I remain to be convinced that the notion of brain birth is a helpful one. We cannot get away from the major differences between a progressive phenomenon which is leading somewhere new, and a once and for all phenomenon which is the final point of an existence that is now at an end. In biological and clinical terms we are dealing with quite separate considerations, and it may be confusing to use the one as a model of the other. The alleged symmetry between the two is not as strong as sometimes assumed and it has yet to be provided with a firm biological base. Further work on this issue will have to take account not only of the issues raised in this paper, but also of the contrast between the order of neural embryogenesis and the disorder of neural death, and therefore of the contrast between the healthy dimensions of brain birth and the pathological dimensions of brain death.

$D$ Gareth fones, BSc MBBS DSc FIBiol is Professor and Chairman, Department of Anatomy, Director of the Neuroscience Research Centre and Director of the Bioethics Research Centre, University of Otago, PO Box 913, Dunedin, New Zealand.

\section{References}

(1) Overhage P, Rahner K. Das problem der hominisation (questiones disputatae 12/3). Freiberg: Herder, 1961.

(2) Ruff W. Das embryonale werden des menschen. Stimmen der zeit 1968; 181:331-355.

(3) Ruff W. Individualitat und personalitat im embryonalen werden. Theologie und philosophie 1970; 45:24-59.

(4) Teilhard de Chardin P. The phenomenon of man. London: Collins, 1959.

(5) Häring B. Medical ethics. Slough: St Paul Publications, 1972.

(6) Curran C. Abortion: law and morality in contemporary Catholic theology. Furist 1973; 33:162-183.

(7) McCormick R. How brave a new world? London: SCM Press, 1981.

(8) Board for Social Responsibility (Working Party on Human Fertilisation and Embryology). Personal origins. London: CIO Publishing, 1985.

(9) Goldenring J M. Development of the fetal brain. New England journal of medicine 1982; 307:564.

(10) Goldenring J M. The brain-life theory: towards a consistent biological definition of humanness. Fournal of medical ethics 1985; 11:198-204.

(11) Kushner T. Having a life versus being alive. Fournal of medical ethics 1984; 10:5-8.

(12) Shea M C. Embryonic life and human life. Fournal of medical ethics 1985; 11:205-209.

(13) Gertler G B. Brain birth: A proposal for defining when a fetus is entitled to human life status. Southern California law review 1986; 59:1061-1078.

(14) Grobstein C. From chance to purpose: an appraisal of external human fertilization. Reading, Mass: AddisonWesley Publishing Co, 1981.

(15) Grobstein C. External human fertilization. Scientific American 1979; 240:33-43.

(Please turn to page 185) 
Any resulting decrease in the overall health of the individual will be a personal decision and is justified by the increase in autonomy and honesty within society.

That doctors would no longer be tied to a principle of confidentiality does not imply that all they learn should be broadcast widely. Just as we avoid gossip in our private lives, so idle discussion of patients' personal information, or the giving of personal details to the media for monetary gain should be shunned. Such actions would be blameworthy because they are impolite and unkind, even where high moral principles are not involved. However, this will be a matter of professional etiquette rather than ethics.

The advantages of my suggestion are obvious. Individual autonomy will be afforded greater respect and will be less frequently harmed by breaches of trust than it is at present. Doctors will no longer face a dilemma when considering cases where they feel personal information about a patient requires action. A final advantage, less tangible but no less valuable, will be a general increase in openness in our society.

It is evident that acceptance of the principle of nonconfidentiality of information revealed to medical practitioners would increase personal privacy and personal autonomy. Whether we ought or ought not to break confidences within the medical sphere is no longer decided by the doctor, but becomes a conscious moral decision made by society. Society must choose. I propose a vote for no confidence.
Sarah Fane Warwick BSc MB ChB MRCGP MA is at present studying for a PhD in Ethics at Manchester University while continuing to work in general practice.

\section{References}

(1) Kottow M H. Medical confidentiality; an intransigent and absolute obligation. Fournal of Medical Ethics. 1986; 12:117-122.

(2) Emson H E. Confidentiality; a modified value. fournal of medical ethics $1988 ; 14: 87-90$.

(3) British Medical Association. Handbook of medical ethics. Landen: BMA, 1984: 69.

(4) Younger report on privacy. Landen: HMSO, 1972: Cmnd 5012, 366

(5) Francis H W S. Of gossips, eavesdroppers and peeping toms. Fournal of medical ethics 1982; 8:134-143.

(6) Parkes R. The duty of confidence. British medical journal $1982 ; 285: 1442-1443$.

(7) Seigler M. Confidentiality in medicine - a decrepit concept. New England journal of medicine 1982; 307:1518-1521.

(8) Chamber's twentieth century dictionary. Edinburgh: Villafield Press, 1985.

(9) Quoted in: Beauchamp T L, Childress J F. Principles of biomedical ethics. Oxford: Oxford University Press, 1983: 230.

(10) Bok S. Secrets: on the ethics of concealment and revelation. Oxford: Oxford University Press, 1984: 20.

(11) Komrad M S. A defence of medical paternalism. foumal of medical ethics 1983; 9:38-44.

(12) We cannot prove privacy necessary for individual functioning. For the present, we may merely state thar such an assumption has been made.

(continued from page 178)

(16) Singer $\mathrm{P}$, Wells $\mathrm{D}$. The reproduction revolution. Oxford: Oxford University Press, 1984.

(17) MacKay D M. The beginnings of personal life. In the service of medicine $1984 ; 30,2: 9-13$.

(18) Edwards R G. Test-tube babies: the ethical debate. The listener 1983 Oct 27:19.

(19) Jones D G. Manufacturing humans. Leicester: InterVarsity Press, 1987.

(20) Anderson C M, Torres F, Faoro A. The EEG of the early premature. Electroencephalography and clinical neurophysiology 1985; 60:95-105.

(21) Lamb D. Death, brain death and ethics. London: Croom Helm, 1985.

(22) Grigg M M, Kelly M A, Celisia G G, Ghobrial M W, Ross E R. Electroencephalographic activity after brain death. Archives of neurology 1987; 44:948-954.

(23) Tooley M. Abortion and infanticide. Oxford: Clarendon Press, 1983. 